\title{
O DISCURSO LITERÁRIO SOBRE AS MASCULINIDADES NOS ANOS 1970: DUAS \\ CRÔNICAS DE LUIS FERNANDO VERISSIMO
}

\section{CHRONICLES OF LUIS FERNANDO VERISSIMO: THE LITERARY ADDRESS ON MASCULINITIES IN THE YEARS 1970: TWO}

\author{
Luiz Carlos Simon \\ Doutor em Ciência da Literatura pela Universidade Federal do Rio de Janeiro \\ Professor do Programa de Pós-Graduação em Letras da Universidade Estadual de Londrina \\ E-mail: luizcssimon@gmail.com
}

\section{RESUMO}

O artigo pretende examinar, sob a perspectiva das masculinidades, parte da produção literária brasileira antes da maior difusão da temática como objeto de estudos e de sua circulação nas diversas expressões da vida cultural. Para favorecer essa avaliação, é feito um levantamento dos últimos quarenta anos quanto aos debates acadêmicos sobre o assunto, autores brasileiros, como Xico Sá e Carpinejar, que escreveram textos nos quais a questão se destaca, e programas televisivos que enfatizam particularidades do comportamento masculino contemporâneo. A análise está concentrada em duas crônicas de Luis Fernando Verissimo escritas e publicadas ainda no início de sua carreira, nos anos 1970, para permitir uma melhor compreensão do retrato de homens construído pelo autor antes da disseminação maior da questão verificada no século XXI. Os resultados, com base na articulação de uma leitura em busca do perfil das masculinidades apresentado nos textos com a investigação sobre o material teórico em torno do assunto, apontam para uma visão crítica e irônica sobre práticas masculinas já naquele tempo.

Palavras-chave: Masculinidades. Crônica. Luis Fernando Veríssimo. Literatura brasileira contemporânea.

\begin{abstract}
This article intends to examine, from the perspective of masculinities, part of the Brazilian literary production before the greater diffusion of the theme as an object of study and its circulation in the different expressions of cultural life. To facilitate this assessment, it is made a survey of the last forty years about the academic debate on the subject. Brazilian authors, as Xico Sá and Carpinejar,
\end{abstract}


who wrote texts in which the question stands, and television programs that emphasize features of the contemporary male behavior. The analysis is focused on two chronic of Luis Fernando Veríssimo that were written and published at the beginning of his career in the 1970s, to allow a better understanding of portrait of men built by the author before the further spread of the question recorded in the twenty-first century. The results, based on the articulation of a reading, searching the profile of masculinities presented in texts, with the research on the theoretical material around the subject, point to a critical and ironic vision of masculine practices already at that time.

Keywords: Masculinities. Chronicle. Luis Fernando Veríssimo. Contemporary Brazilian Literature.

O desejo de interpretar a chamada crise das masculinidades nos dias atuais pode conduzir, a princípio, à ideia de que se está essencialmente diante de um fenômeno muito recente, típico desses primeiros anos do século XXI. É natural que isso aconteça. Não faz tanto tempo que a matéria circula pelos diversos ambientes, sejam eles acadêmicos ou não. Para iniciar a análise desta circulação, é possível recorrer à movimentação editorial e seus fortes vínculos com as pesquisas desenvolvidas no espaço universitário. Pode-se afirmar, com segurança, que R. W. Connell é, há vinte anos ou mais, uma das maiores referências nos estudos sobre masculinidades no âmbito internacional. Com artigos publicados especificamente sobre o assunto desde a década de 1980, é em 1995 que seu livro Masculinities lhe assegura a projeção na abordagem da questão. Dez anos mais tarde, na segunda edição da obra, preparada nos Estados Unidos e acrescida de introdução e posfácio, as referências bibliográficas contidas no volume constituem um rico conjunto de fontes sobre os estudos da temática: são quase trinta páginas de títulos, entre livros e artigos publicados em periódicos, que versam sobre as masculinidades e assuntos correlatos, como estudos de gêneros, de organização familiar, feminismos e homossexualidade, entre outros. Nesse farto material, não chega a duas dezenas o total de livros - de autoria individual ou coletiva específicos sobre masculinidades editados antes de 1980, o que comprova a condição ainda incipiente da questão em âmbito universal, naquele momento, uma vez que os títulos reunidos por Connell são publicações feitas em países muito diversos, como Austrália, Estados Unidos, África do Sul, Alemanha, Japão, Brasil, Índia, México, Rússia, Turquia, França, Argélia, entre outros.

No contexto brasileiro, é preciso reconhecer que o interesse mais aprofundado sobre a experiência masculina como objeto de estudo ocorre ainda depois. Se, em outros lugares do mundo - ganham destaque Austrália, Estados Unidos e o Reino Unido -, é apenas na penúltima década do século XX que o tópico suscita investigações e publicações mais extensas, as iniciativas brasileiras 
de pesquisas nesta área demoram cerca de dez anos a mais para se materializar. Um dos pioneiros é Sócrates Nolasco, que, em 1993, lança seu livro O mito da masculinidade e apenas dois anos mais tarde reúne em outro volume, A desconstrução do masculino, artigos de diversos autores com formações e atuações em variadas áreas do conhecimento dispostos à reflexão acerca do comportamento dos homens. Sem dúvida, um motor deste interesse é a percepção de que a sociedade brasileira finissecular já revelava e produzia alterações naqueles comportamentos.

O antropólogo e também professor de Comunicação Carlos Alberto Messeder Pereira, um dos colaboradores do livro organizado por Nolasco, tem sua observação atraída para uma prática masculina em evidência na vida cultural brasileira nas duas últimas décadas do século XX: o strip tease transformado em espetáculo com grande sucesso em casas de show de Copacabana, inicialmente para um público gay e depois incorporando o público feminino, e logo absorvido por uma telenovela que foi ao ar em horário prestigiado, com audiência expressiva. Ao se cercar de termos centrais - exibicionismo, sensualidade, ambiguidade e simulação - para sua interpretação do fenômeno, o estudioso prepara o terreno para certas constatações em torno da redefinição do perfil masculino: a “confusão' contemporânea entre os gêneros” (PEREIRA, 1995, p. 56) e o esgotamento de oposições simplistas e naturalizadas entre o masculino e o feminino e entre heterossexualidade e homossexualidade. O strip tease dos homens, capaz de lhes firmar uma nova expressão e condição, a de "homem objeto", não se restringia a um acontecimento isolado dentro de um quadro que deixava de se caracterizar por noções como estabilidade e identidade.

Uma visão semelhante que se volta para o mesmo período de tempo, as duas últimas décadas do século XX, é a que se percebe na análise empreendida por Marko Monteiro a propósito de revistas masculinas brasileiras publicadas naquele momento:

Uma das principais características dessas novas formas de representação é a objetificação do masculino ou a crescente sexualização da imagem do homem nas páginas das revistas, fenômeno que ocorre também em outras mídias. O homem passa a ser visto como objeto de desejo, a ser consumido prazerosamente pelo olhar do(a) leitor(a), convenções tradicionalmente aplicadas às mulheres na sua representação (MONTEIRO, 2013, p. $352)$.

Quanto ao território das manifestações literárias, é necessário cercar-se de cuidados e proceder à releitura minuciosa de diversas obras, inclusive aquelas já consagradas, que podem proporcionar reavaliações segundo perspectivas empregadas que privilegiem a questão da masculinidade e de como essa instância pode interferir sobre construção de personagens, desdobramento de tramas e constituição de discursos. Assim, é viável retomar Bentinho em Machado de Assis, Sérgio d'O Ateneu, de Raul Pompéia, Frederico Paciência, do conto homônimo de Mario de Andrade, Paulo Honório, em Graciliano Ramos, e ainda Riobaldo ou Diadorim, em 
Guimarães Rosa, limitando a apenas alguns exemplos canônicos da prosa brasileira, para instaurar ou reafirmar outras formas de apreciação destas produções literárias nas quais o componente masculino pode suscitar análises profícuas. De qualquer modo, por mais que um alto grau de genialidade e sensibilidade marque a trajetória dos autores citados, é inevitável averiguar que a configuração de práticas masculinas sofra, com maior intensidade, a influência de transformações mais profundas em papéis e identidades associadas à constituição de gêneros a partir do período correspondente as duas ou três últimas décadas do século XX. Nessa faixa de tempo, ainda no contexto brasileiro, já transitam outros prosadores como Caio Fernando Abreu, Roberto Drummond, João Gilberto Noll, Edgard Telles Ribeiro, Sérgio Sant’Anna, Moacyr Scliar e Luiz Vilela, aptos, pela afinidade e sintonia com o tempo vivenciado, a expor uma construção ficcional mais impregnada das experiências perturbadoras a que os homens eram submetidos no plano das relações de gêneros. De fato, focalizar as masculinidades e seus processos de ajustes às dinâmicas mais recentes e plurais das constituições e interações entre os gêneros nas obras de qualquer um destes autores será garantia de fartura no investimento. Com certeza, no cenário movimentado dos anos 1980 e 1990, não são apenas esses escritores que propiciam uma abordagem da redefinição masculina. Ao mesmo tempo, o fundamento do interesse de um estudioso por aqueles romances e contos não será necessariamente a masculinidade, o que implica reconhecer que, naquelas obras, ainda não sobressai tanto a temática, que ela não é tão evidente ou central. Essa grande visibilidade vai se concretizar mesmo no século XXI.

Dois cronistas podem ser reconhecidos como autores que trazem a questão masculina para um primeiro plano a partir dos anos 2000: Xico Sá e Carpinejar. O primeiro foi, ao lado de Fernando Bonassi, responsável pela coluna "Macho", que circulou na Folha de S. Paulo de 1997 a 2004, e publicou livros com títulos inequívocos: Modos de macho \& modinhas de fêmea: a educação sentimental do homem (2003); Chabadabadá: aventuras e desventuras do macho perdido e da fêmea que se acha (2010); e Os machões dançaram: crônicas de amor \& sexo em tempos de homens vacilões (2015). O primeiro e o último volume da trilogia são divididos em partes cujos títulos deixam transparecer com clareza a intensidade do foco na questão masculina como marca das publicações: no primeiro, há seções como "A educação sentimental do macho", "Marcação homem a homem" e "Madeleines e bodes em geral de um cabra"; no mais recente, metade das crônicas do livro está incluída em duas partes intituladas "Tipinhos de homens" e “Quando um homem ama uma mulher”. No segundo volume, apresentado sem subdivisões, vários títulos de crônicas podem ser citados para ilustrar a ênfase da edição: "Sensibilidade \& macheza a origem", "Da peleja do metrossexual contra o macho-jurubeba", "Do macho tupperware ou O homem é um prato feito que se come frio mesmo", "O homem-projeto, a obra aberta e o macho 
inacabado", "Oncotô, proncovô - o homem no mato sem cachorro ou GPS", "O cafa amador e o cafa que ama", "O homem, a lenda, o mito do falso Don Juan", "Faz de conta que sou o primeiro", “O supermacho à luz da patafísica", "O cabra-macho à luz do lampião propriamente dito" e "Mocó de um velho homem solteiro".

Após o primeiro livro de crônicas publicado em 2005, O amor esquece de começar, Carpinejar, também poeta, jornalista e professor, aderiu com vigor ao ofício de cronista e publicou entre outros volumes: Canalha! (2008), Mulher perdigueira (2009), Borralheiro: minha viagem pela casa (2011), Ai meu Deus, ai meu Jesus: crônicas de amor e sexo (2012), Espero alguém (2013), Curinga (2014) e Para onde vai o amor? (2015). Embora alguns dos títulos não indiquem tão explicitamente o teor das crônicas, seu vínculo com as práticas masculinas e o esforço para representar um perfil de homem que se afasta do padrão hegemônico, a transcrição dos títulos de diversos textos reunidos nos livros pode cumprir esse papel: "Pai materno", "O que um homem quer?", “Adorável canalha”, “O canalha arrependido", “Conversa de homem”, "Homem perfeito”, "Pau duro", "Não se come uma mulher", "Banheiro masculino”, "Infidelidade masculina”, "Gay heterossexual", "Cueca no box", "Esqueço que tenho um pau”, "Tarado", "Aumente sua delicadeza até 28cm", "Para que servem os homens", "Quando o homem fingir o orgasmo", "Casado na festa de solteiro", “Já broxou?”. São apenas alguns exemplos evidentes da recorrência da temática no trabalho do cronista e do lugar que ela ocupa como matéria central de seu ofício.

O destaque aos dois autores não pode ser interpretado como uma particularidade de seus estilos que esteja desvinculada de um movimento mais amplo nessas duas primeiras décadas do século XXI no Brasil. Entre cronistas do período, devem ser ressaltados também Fernando Bonassi, que assinou a já referida coluna "Macho", na Folha de S. Paulo, e teve alguns dos textos daquela seção selecionados para a publicação As melhores vibrações: um livro sobre sexo para homens e mulheres de todos os sexos (2002), e Marcelo Rubens Paiva, assíduo nas colaborações para a imprensa e autor de $O$ homem que conhecia as mulheres (2006). Além dessas manifestações na esfera da literatura, cabe salientar que a televisão também se abre para iniciativas de representação das experiências masculinas como assunto principal: entre 2003 e 2004, após algumas inserções no programa dominical Fantástico da Rede TV Globo, vai ao ar a série Sexo frágil, estrelada por atores talentosos como Lázaro Ramos e Wagner Moura, promessas na época; e em 2011, é a vez de Macho man, com Jorge Fernando e Marisa Orth no elenco. Na redação dos episódios, havia a participação de nomes que também circulam pelo meio literário, como Marcelo Rubens Paiva e Antônio Prata. E ainda é o caso de mencionar que um programa de debates longevo e de grande êxito como o Saia justa, desde 2002 concebido para ser um veículo de ideias apresentadas sob a perspectiva feminina, tem abertura gradativa para intervenções masculinas, 
como as dos atores Eduardo Moscovis e Dan Stulbach, do músico Leo Jaime e de Xico Sá, até que a partir de 2012 eles assumem a incumbência de substituir as apresentadoras durante as férias. Não se pode imaginar que, nesta temporária atribuição, os homens pretendessem reverter a orientação inicial do programa. Assim, cabia ao quarteto respeitar o espírito dos debates, podando posicionamentos sexistas, sobretudo aqueles que pudessem ferir, eventualmente, as suscetibilidades femininas.

Este quadro diversificado e detalhado, com referências do universo literário, televisivo e acadêmico, aponta para o reconhecimento da virada do século XX para o século XXI como o grande momento para a eclosão das masculinidades como temática a circular com maior desenvoltura. Provavelmente é mesmo a avaliação mais segura no que se refere ao contexto brasileiro, ainda que, até os anos 1960, dois cronistas, adeptos do humor, tenham produzido textos em que já se esboçava um perfil significativo para a representação dos homens: Antônio Maria e Sérgio Porto, ambos mortos precocemente antes dos cinquenta anos. De qualquer modo, um nome até agora suprimido tem papel fundamental na trajetória dos debates sobre a condição masculina na contemporaneidade. Luis Fernando Verissimo foi o idealizador da já mencionada série Sexo frágil, e antes disso integrou a equipe de roteiristas de outro programa televisivo fundamental para o exercício de reformulação do humor na teledramaturgia brasileira, a TV Pirata, que estreou em 1988 e prosseguiu até 1992. Atuou ainda como roteirista e foi inspiração principal da premiada série Comédias da vida privada - título derivado de sua antologia de crônicas publicada em 1994 exibida entre 1995 e 1997. Além das retransmissões, exportações e dos prêmios obtidos, o prestígio dos dois programas pode ser medido pelos atores e atrizes reunidos no elenco: Marco Nanini, Ney Latorraca, Marieta Severo, Regina Casé, Otávio Augusto, Fernanda Torres, Diogo Vilela, Débora Bloch, Pedro Cardoso, Pedro Paulo Rangel, Luiz Fernando Guimarães, Andréa Beltrão, Cláudia Raia, Cláudia Abreu, Guilherme Karam, Louise Cardoso e Marisa Orth foram alguns dos que participaram dos episódios.

No que se refere às produções de Verissimo para circulação impressa - os textos encaminhados à imprensa e que mais tarde migram para as livrarias -, é importante considerar que, no ano do surgimento da coletânea Comédias da vida privada, já havia mais de uma dezena de títulos em sua carreira de autor de livros de crônicas iniciada com O popular, em 1973, e que teve na sequência, entre outros, A grande mulher nua (1975), Amor brasileiro (1977), Ed Mort e outras histórias (1979), Sexo na cabeça (1980), O analista de Bagé (1981), Outras do analista de Bagé (1982), A velhinha de Taubaté (1983), A mulher do Silva (1984), A mãe do Freud (1985), O marido do Dr. Pompeu (1987), Orgias (1989), Peças íntimas (1990) e O suicida e o computador (1992). 
É necessário reconhecer que, na obra de Verissimo, o enfoque das masculinidades não desempenha papel tão evidente quanto nas produções de Xico Sá e de Carpinejar. Seria, por exemplo, mais difícil recorrer ao expediente de selecionar e transcrever títulos de crônicas de Verissimo para ilustrar a ênfase na configuração dos homens e seus ajustes e desajustes contemporâneos. Isso, entretanto, não significa pouca consideração dedicada ao assunto. As diversas histórias protagonizadas por Ed Mort e pelo Analista de Bagé já constituem exemplos desse retrato cruel imposto ao homem. O detetive é invariavelmente um profissional que exibe sua incompetência, embora às vezes até elucide alguns casos. Diante das clientes exuberantes, sucumbe em meio ao cenário desolador de seu escritório repleto de baratas, que são invencíveis antagonistas. Até manter mobília e a plaqueta na porta torna-se desafio complexo para o investigador. O truculento psicanalista, ao fornecer soluções esdrúxulas para os problemas que lhe são apresentados, propicia um modo de ironizar ora a tradicional brutalidade demonstrada pelo terapeuta ora as indefinições masculinas dos pacientes. Assim, diferentes formas da ação dos homens servem à pena crítica e cômica do cronista. Além desses textos, o farto material construído por Verissimo no decorrer de mais de vinte anos permitiu a concretização da ideia de uma antologia - as Comédias da vida privada - concentrada em situações típicas vividas por homens e mulheres da classe média. Como partes desse painel, sobressaem as figuras do pai, do marido, do ex-marido, do namorado, do amante, do amigo que se junta a outros amigos, do jovem que quer seduzir alguém, do vizinho, do colega de trabalho. Todos eles entram para a galeria de Verissimo e contribuem para a multiplicidade dos tipos masculinos disponibilizados pelo autor.

A experiência de reler crônicas do início da carreira de Verissimo, independentemente da motivação, é muito gratificante. As risadas não excederam o prazo de validade. Percebe-se, com isso, que os perfis ali esboçados mantêm sintonia com os dias correntes. Essa constatação favorece o reconhecimento do autor que, embora desfrute de enorme êxito no mercado, corre o risco de ser pouco identificado com o conjunto de escritores mais prestigiados do momento. Esse "instantaneísmo" marcante no presente contamina tanto os leitores diletantes de diferentes idades quanto os jovens que ingressam no ensino superior e nos cursos de pós-graduação. Além disso, o fato de Verissimo ser reconhecido como cronista pode levar à avaliação de que textos seus escritos há quarenta anos ou mais já estão datados, predispondo mais uma vez a troca por alguém cuja assinatura seja mais fresca. No que diz respeito à questão das masculinidades, o exercício da releitura também é produtivo para que se examine a situação a que o homem representado é exposto e ainda o modo com que o autor aborda e focaliza as peculiaridades do trânsito masculino. Em ambos os casos, é relevante analisar as conexões da época em que os textos foram escritos com as experiências mais recentes. 
A escolha de duas crônicas que constam do segundo livro de Verissimo, A grande mulher nua, publicado em 1975, não deixa de ter ares de retrato de uma época. A distância entre o ano de publicação e o tempo presente cria, portanto, certa expectativa: trata-se de outro momento, hoje já superado, ou deve-se entendê-las como textos fundadores de um modelo de discurso que se iniciou lá, mas persiste e se torna inclusive mais frequente atualmente. É o olhar mais minucioso para as duas crônicas selecionadas - "Persuasão" e "Dezesseis chopes" - que tende a nos aproximar da resposta ou, no mínimo, ensejar a reflexão mais circunstanciada sobre o percurso das masculinidades, em articulação com o material teórico produzido sobre o assunto.

"Persuasão" é um texto escrito integralmente sob o formato de diálogo, sem uma intervenção sequer do narrador. Trata-se de modelo bastante utilizado por Verissimo e também por cronistas de gerações anteriores, como Carlos Drummond de Andrade e Fernando Sabino. Não representa, assim, uma grande inovação no gênero, embora se afaste de uma de suas peculiaridades, que é o comentário da cena, muitas vezes elaborado com um componente lírico. Essa retração do narrador pode insinuar que haja alguma dificuldade para a interpretação dos discursos apresentados no texto até porque ficam disponíveis apenas as falas das personagens que mantêm o diálogo. Cabe considerar que, para a natureza do diálogo exposto na crônica, a supressão do narrador revela-se recurso adequado para a construção do texto: a conversa transcorre entre um homem e uma mulher, provavelmente casados, embora nada impeça que sejam namorados com mais tempo de convivência ou maiores intimidades sexuais. O casal está na cama, e a ideia de persuasão, presente no título da crônica, pode corresponder, numa primeira leitura, à tentativa do homem para convencer sua parceira a praticar alguma novidade no ato sexual, algo que se diferencie dos hábitos mais comuns daquele relacionamento. Também não tem nitidez no texto qual é a inovação proposta pelo homem. Pode ser, por exemplo, sexo anal, ou ainda outra prática tida como audaciosa que leva a mulher a oferecer resistência, como se vê em suas primeiras reações ao assédio do parceiro: "Não insista. [...] Eu só acho que nestas coisas a gente deve ir devagar. Dar tempo ao tempo. [...] Pára, eu já disse.” (VERISSIMO, 1976, p. 137). As indefinições em torno de certos detalhes da relação entre o casal não são suficientes, porém, para bloquear avaliações da atuação masculina representada pelas falas e pelos movimentos do homem. A insistência da personagem beira à obsessão, e, nesse sentido, no primeiro momento da crônica, essas falas e ações convergem para a mesma meta e direção - a concretização do ato sexual de acordo com o desejo dele -, indicando um traço reconhecido como tradicional da versão mais previsível do padrão masculino de comportamento: “A ação, o fazer, o realizar e o desempenho colocam os homens continuamente diante da questão do uso e da legitimidade de seus comportamentos." (NOLASCO, 1995, p. 25). Tanto a ideia de desempenho quanto a noção de 
legitimidade são relevantes para uma articulação com a crônica. As falas, que correspondem à argumentação, e os movimentos, que são aproximações corporais, têm amparo no desejo, que, naquele momento, pela ótica do homem, precisa se materializar em desempenho sexual, algo que é perfeitamente legítimo e está em sintonia com as práticas que sustentam a ideia de masculinidade hegemônica, apresentada por Connell (2005, p. 77). Portanto, a argumentação desenvolvida perante a companheira é uma forma de garantir legitimidade para a consumação daquele tipo de desejo, que, por sua vez, vai viabilizar a exibição de um desempenho sexual específico, que não poderia se manter inédito, armazenado, na condição de não experimentado. O homem de "Persuasão" prepara-se, assim, para participar de uma das provas de masculinidade, que, conforme análise de Michael Kimmel (1998, p. 112), consiste no desempenho do papel de desbravador, a imagem do homem que, munido de coragem, enfrenta riscos para superar obstáculos. Arriscar novas posições sexuais ou outros formatos de atos sexuais está também associado a sua condição masculina: "Temos que aproveitar a vida agora. Hoje. Fazer tudo, provar tudo..." (VERISSIMO, 1976, p. 137). Assim como desempenhar o papel de desbravador, de percorrer terras inóspitas e de batalhar para conquistá-las está no programa masculino, é preciso, também no âmbito da sexualidade, desbravar, explorar, ousar, abdicar da moderação.

É essa falta de comedimento que impulsiona e dá o tom em sua argumentação. E a dramaticidade empregada no exercício da persuasão será responsável pelo rumo diferente para o diálogo. Logo no início de seus argumentos, a carga dramática se manifesta: "Mas o mundo está acabando mesmo! Você não lê os jornais? Tá chegando no fim. Não há mais tempo para nada." (VERISSIMO, 1976, p. 137). Diante da relutância de sua parceira, os argumentos vão se desdobrando: além do fim do mundo, são trazidos à tona a aproximação do cometa como um indício apocalíptico, a crise generalizada decorrente da falta de produtos variados como gasolina, água e alimentos e a iminência de uma guerra: “O fimm não tarda. O fim pode ser amanhã mesmo!" (VERISSIMO, 1976, p. 138). A enumeração de situações fatalistas passa a ser acompanhada da exaltação progressiva no discurso do homem que pode ser avaliada pelas brevíssimas interrupções da mulher: "Agora você ficou brabo. [...] Não fica exaltado, bem. [...] Querido...” (VERISSIMO, 1976, p. 138). A exasperação do homem não permite sequer que as falas da mulher sejam mais longas, uma vez que o discurso indignado atropela as participações da interlocutora; nem é mais necessário que ela resista às investidas do parceiro, pois o foco deste deixou de ser o apelo sexual, cada vez mais esquecido. À mulher cabe agora deter o controle de outra espécie de ânimo. A apreensão, causada pelo destempero crescente de seu companheiro, é tanta que ela resolve mudar de atitude na tentativa de tranquilizá-lo: "Vem cá. Te acalma, puxa. Encosta aqui. [...] Está certo, você me convenceu.” (VERISSIMO, 1976, p. 138). O homem, absorvido por sua própria ladainha 
apocalíptica, nem mesmo ouve a capitulação expressa pela penúltima frase e ainda demora a registrar o sentido da última: "Ratão de esgoto, ouviu bem? E sem sal, que também vai faltar. Como, te convenci?" (VERISSIMO, 1976, p. 138). É como se o homem já estivesse confuso: convencer de quê? Da plausibilidade do fim do mundo, da crise generalizada e de seus perigos ou da mera proposta proferida no início da conversa do casal? A esta altura, o contexto sexualizado do diálogo parece totalmente engolido pelo discurso da crise. O rato e o esgoto contaminaram o desejo e a iniciativa de uma variação excitante na rotina sexual. A parceira, contudo, ainda move esforços para relembrá-lo da natureza da persuasão e esclarece: "Me convenceu. Agora eu quero. Você tem razão, temos que aproveitar a vida antes que a crise tome conta. Vamos." (VERISSIMO, 1976, p. 139). O homem, no entanto, não vai. É tarde para recuperar aquele ímpeto. Suas últimas frases, imediatamente após aquele chamamento - "Vamos.", que era a resposta aguardada por ele no início do diálogo -, denotam que é ele quem capitula: "Peraí um pouquinho. [...] Pois é, mas agora fiquei meio deprimido." (VERISSIMO, 1976, p. 139). Não só a depressão, mas também a confissão da depressão apontam para fortes conexões entre vida sexual e vida social, instâncias que pareciam independentes. Uma das consequências destes cruzamentos é o abalo sofrido pela virilidade masculina, reduto supostamente imune, dado como livre da ação de qualquer elemento externo.

Em “Persuasão", Verissimo expõe completamente o homem. Sem recorrer a um narrador que intervenha sobre a cena focalizada, são as falas da própria personagem e suas interações com outra personagem feminina que revelam a essência do representante masculino. Neste sentido, nas frases iniciais, não surpreende o leitor defrontar-se com uma proposta, feita por um homem, para apimentar a vida sexual de um casal. Aliás, é este o mote de um conto de Luiz Vilela, "Ousadia”, publicado inclusive antes da crônica de Verissimo, em 1970. A ideia de um homem obcecado por sexo e que quer impor à mulher seus desejos e sua perspectiva está dentro da previsibilidade no que se refere a padrões esperados para as práticas masculinas. O que pode escapar desse território do previsível não é sequer a estratégia de argumentar a favor do próprio desejo, de querer legitimá-lo, o que pressupõe ainda desconsiderar o desejo alheio, passo significativo especialmente pelo fato de ser este desejo feminino. As surpresas começam quando o homem revela a adesão ao espírito de seus próprios argumentos. A partir desse arrebatamento, as ousadias sexuais são preteridas, e o sentimento apocalíptico e suas consequências sobre o ânimo da personagem masculina ocupam o espaço antes reservado à sensualidade. Assim, o desfecho da crônica representa um golpe sobre a noção de uma virilidade que esteja acima de quaisquer ameaças. A certeza de que há uma crise não deixa intacta a masculinidade, o que conduz à afirmação da vulnerabilidade não mais como inscrição estranha ao perfil masculino, mas como um risco absolutamente concreto. 
A organização narrativa da crônica "Dezesseis chopes" é diferente da que aparece em "Persuasão". A presença de um narrador externo à ação, que se encarrega de apresentar personagens e espaço, não é tímida. O discurso direto é pouco utilizado e convive com várias passagens em que se manifesta a ocorrência do discurso indireto livre. O recurso é interessante, pois oferece situações em que as perspectivas de narrador e personagens podem se confundir, dificultando um pouco a delimitação daquilo que pertence a um e a outro. No caso específico desta crônica, como o próprio título indica, a fusão dos discursos ganha um atrativo a mais: a relação instável entre embriaguez e sobriedade.

São cinco amigos homens reunidos para conversar diante de uma mesa de bar. $\mathrm{O}$ narrador, na condição de observador, assume a responsabilidade de dividir em etapas a permanência dos amigos no bar, de acordo com o número de rodadas de chopes ingeridos: o início insosso das primeiras rodadas; a fase das anedotas, do terceiro ao quarto chope; o futebol, do quinto ao sexto; a "etapa das graves ponderações", a partir do sétimo; a confidencial, após a nona rodada; a "etapa inteligente", depois de dez ou onze chopes; e finalmente a "fase da nostalgia" após quinze rodadas (VERISSIMO, 1976, p. 78-79). Essa mistura de contabilização de rodadas com a atribuição classificadora de etapas produz um contraste com a dinâmica das personagens no bar, que provavelmente seriam incapazes de quantificar os chopes bebidos e teriam dificuldade maior ainda para reconhecer e caracterizar a natureza de suas conversas. Esse contraste é um componente que contribui para estabelecer distância entre o narrador e as personagens, para reforçar as associações da sobriedade com o primeiro e da embriaguez com os últimos. Ao mesmo tempo, estas classificações garantem ainda ao narrador um ar de comprometido com a observação fria, séria, distanciada, objetiva, enquanto às personagens resta a condição de frívolos e irresponsáveis. Essa polarização não evita que o narrador forneça uma apresentação condescendente dos frequentadores do bar focalizados: "São homens feitos, homens de sucesso, amigos há muitos anos." (VERISSIMO, 1976, p. 79). Identificá-los como homens que desfrutam de êxito pode até contribuir para reduzir a carga de frivolidade com que as personagens são descritas, porém, mais relevante do que essa espécie de trégua é a fixação da imagem deles como representantes masculinos prestigiados, e consequentemente a explicitação de que esse prestígio, essa ocupação do topo da pirâmide, persiste mesmo na coexistência com atitudes banais e fúteis. Neste sentido, a exposição daqueles homens como "homens de sucesso" leva a interpretar essa condição de prestígio com reservas e não com a presunção de que o sucesso deriva de méritos indiscutíveis. Verissimo ainda escancara a cumplicidade entre os homens - outro conceito caro a Connell (2005, p. 79), que está associado aos ganhos masculinos sem ter que se recorrer a uma demonstração ostensiva de autoridade - na passagem em que, após a ameaça de um deles ir 
embora, surge uma espécie de resolução conjunta que deverá ser respeitada por todos da mesa: "Hoje ninguém vai pra casa." (VERISSIMO, 1976, p. 79). Não se sabe se este que quis deixar o bar era casado ou solteiro; aliás, isto parece não vir ao caso. De qualquer modo, as esposas não são sequer figurantes da crônica, e a ideia de uma permanência indeterminada no bar soa como um salvo-conduto que inclusive libera aqueles homens de quaisquer responsabilidades conjugais ou domésticas. Portanto, a masculinidade em sua totalidade, mas, sobretudo, a versão hegemônica, é posta em evidência. Outras passagens da crônica reforçam esta ideia. A chamada "etapa inteligente" - a própria expressão representa forte ironia do narrador sobre o estágio da conversa é assim caracterizada: "Todos dizem frases definitivas que nenhum ouve, pois cada um grita a sua ao mesmo tempo. [...] Começa uma discussão, ninguém sabe muito bem se sobre palitos ou petróleo.” (VERISSIMO, 1976, p. 79). As frases definitivas e sem repercussão, os gritos concomitantes e a discussão sobre assunto desconhecido compõem um quadro muito pouco próximo da inteligência.

A etapa subsequente, da nostalgia, também é marcada pela percepção de que a linguagem do grupo já se encontra desarticulada e se mostra incapaz de ultrapassar qualquer centímetro além da trivialidade: "As grandes revelações. Eu sou uma besta... Besta sou eu. Tenho que mudar de vida. Eu também. Cada vez me arrependo mais de não ter... de não ter... sei lá!” (VERISSIMO, 1976, p. 79). Impotentes para elaborar uma frase autêntica que expresse a própria insatisfação desencadeada pelas reminiscências, cada um se restringe a repetir as lamúrias alheias ou emitir frases que, embora simplórias, não chegam a se completar. Assim, essa atmosfera nostálgica que, aliada à embriaguez, leva as frases dos integrantes do grupo a se tornarem incompletas está ligada também àquilo que Badinter vê como um movimento tipicamente masculino: a "imagem inacessível da virilidade acaba suscitando nos homens a percepção de que são incompletos." (BADINTER, 1993, P. 137). A animação de etapas anteriores não consegue ser preservada; é substituída por lamentações e lástimas que já não correspondem também à referida condição de "homens de sucesso", mas estão mais próximos do fantasma da incompletude.

É nessa atmosfera que um dos convivas se dispõe a anunciar seu ressentimento maior. Cria-se a expectativa para a revelação até porque também se aproxima o desfecho da crônica, e o homem profere a mesma pergunta três vezes com mínimas variações, produzindo suspense e a impaciência dos companheiros: "Sabe o que é que eu sinto, mas sinto mesmo? [...] Sabe qual é a coisa que eu mais sinto? [...] Sabe qual é o vazio que eu mais sinto aqui?" (VERISSIMO, 1976, p. 79-80). Diante da demora dramática na revelação e da insistência dos colegas, ele finalmente confessa sua grande mágoa: "É que eu nunca tive um canivete decente.” (VERISSIMO, 1976, p. 80). A exposição do ressentimento gera silêncio e consternação na mesa, tão poderosos que o 
garçom se aproxima para verificar o que acontecera. A passagem é significativa e requer transcrição também por conter uma participação peculiar do narrador: "Encontra os cinco subitamente sóbrios, olhando para o centro da mesa com o ressentimento de anos. É isso, é isso. Um homem precisa de um canivete. [...] Um verdadeiro canivete. Pesado, de fazer volume na mão, com muitas lâminas. Um canivete decente.” (VERISSIMO, 1976, p. 80).

A sobriedade retorna à mesa com o aval do narrador. Não é apenas o garçom que detecta a mudança de estado naqueles homens que minutos antes eram vistos como irreversivelmente ébrios. A intervenção do narrador já não se descola tão facilmente da perspectiva dos homens ao redor da mesa: é o narrador ou são eles que chegam à conclusão de que um homem precisa de um verdadeiro canivete? As carências masculinas são materializadas pela falta do canivete e parecem sensibilizar o narrador que passa a reconhecer a gravidade do instante. De qualquer modo, a ideia de incompletude na constituição masculina ganha evidência e é ainda enfatizada pela manifestação de outro integrante da mesa que, algum tempo após a revelação do amigo, tem a oportunidade de fazer sua própria revelação, curta e bombástica: "Eu tive.” (VERISSIMO, 1976, p. 80). A reação à frase do homem que confessa ter tido a posse de um canivete decente confirma e acentua a comoção dos presentes: "E os outros olham para ele como se olha para um homem completo. Ali está o melhor deles, e eles não sabiam.” (VERISSIMO, 1976, p. 80). O registro do narrador acompanha a comoção daqueles homens e conclui a crônica, deixando cenas expressivas para a abordagem das masculinidades.

A condição de homens de sucesso atribuída às personagens antes da metade do texto convive com as ironias do narrador quanto às variadas etapas e rodadas de chope durante a permanência dos amigos no bar. A etapa "inteligente" e a fase da nostalgia são destaques e proporcionam material farto para se exercitar o deboche sobre as práticas masculinas. O episódio do canivete e a desolação dos companheiros de mesa é o fecho certeiro para o conjunto de desnudamentos de fragilidades, vulnerabilidades e carências dos homens. Neste sentido, os limites tênues na crônica "Dezesseis chopes" entre sobriedade e embriaguez, entre inteligência e incomunicabilidade, entre animação e prostração reforçam a instabilidade masculina, permitindo que se vislumbre um diagnóstico sombrio para os homens.

Aparentemente, as duas crônicas selecionadas têm poucos pontos comuns. Enquanto "Persuasão" é escrita sob a forma de diálogo, sem qualquer intervenção do narrador, "Dezesseis chopes" têm poucas falas das personagens e um narrador que assume a condução do texto e proporciona diversas passagens com o recurso do discurso indireto livre. Quanto às cenas focalizadas, a cama e o casal da primeira crônica constituem um ambiente privado e propiciam o 
enfoque da sexualidade e seus detalhes íntimos. A mesa de bar e sua composição integralmente masculina na segunda crônica sinalizam para a exclusão feminina e para a emergência de expressões coletivas do comportamento dos homens no espaço público.

No entanto, a ansiedade da personagem masculina de "Persuasão", que a leva tanto a querer introduzir e impor práticas sexuais diferentes na rotina do casal quanto a se exaltar e se deprimir com o alarmismo e o próprio discurso fatalista, encontra paralelos no grupo de "Dezesseis chopes”, que em sua fase decisiva, a nostálgica, inicia um processo de exteriorização de reminiscências, lamentações e arrependimentos. O tempo assombra os homens das duas crônicas e os força a desejar mudanças de rumos ou restaurações da trajetória já percorrida, nem que o instrumento dessa recuperação seja um mero canivete.

Ao abordar as ideias da virilidade como um mito e da potência muscular como marcas do imaginário masculino no presente, Jean-Jacques Courtine faz a seguinte avaliação: “A hipermasculinidade contemporânea carrega em profundidade a marca dessa recusa da morte, essa nostalgia de um tempo anterior e essa paixão regenerativa pela força da idade" (COURTINE, 2013, p. 567). Embora a obsessão com os músculos e o envelhecimento com suas consequências e ameaças sobre a virilidade não sejam questões evidentes nas duas crônicas selecionadas, é possível constatar nos impulsos daqueles homens os anseios de redesenhar percursos seja através das práticas sexuais seja através da confissão de ressentimentos e carências que incomodam e alimentam o sentimento de incompletude.

Dessas inquietações Verissimo não se esquiva. Ao expor um homem que quer persuadir sua companheira a ter atos sexuais com inovações e depois exibi-lo como incapaz para concretizar o que fora proposto, o autor ironiza a volúpia masculina e a coloca sob a interferência de fatores sociais externos que podem comprometê-la. Ao apresentar um grupo de homens de sucesso que discorrem sobre diversos assuntos na mesa do bar até a conclusão de que a falta de um canivete é decisiva para o vazio de suas trajetórias, o autor também ironiza o suposto sucesso masculino e seus mecanismos de perpetuação que convivem com queixas e insatisfações. Se não há, ainda, a representação inequívoca de uma crise da masculinidade nem o esboço de um perfil de homem mais sintonizado com relações de gênero igualitárias, já se manifestam perturbações experimentadas na vida masculina que ficam à mercê do aguçado senso crítico e irônico do cronista que proporciona a autores mais jovens a consolidação de um modelo de representação desses impasses. São as contribuições de Verissimo, no início de sua carreira, que se adiantam, assim, a todo um cenário caracterizado pela circulação de intenso debate sobre as masculinidades. 


\section{REFERÊNCIAS}

BADINTER, Elisabeth. XY: sobre a identidade masculina. $2^{\mathrm{a}}$ ed. Rio de Janeiro: Nova Fronteira, 1993.

BONASSI, Fernando. As melhores vibrações: um livro sobre sexo para homens e mulheres de todos os sexos. São Paulo: Publifolha, 2002.

CARPINEJAR. O amor esquece de começar. $2^{\mathrm{a}}$ ed. Rio de Janeiro: Bertrand Brasil, 2006.

. Canalha! Rio de Janeiro: Bertrand Brasil, 2008.

Mulher perdigueira. $2^{\mathrm{a}}$ ed. Rio de Janeiro: Bertrand Brasil, 2010.

. Borralheiro: minha viagem pela casa. Rio de Janeiro: Bertrand Brasil, 2011.

. Ai meu Deus, ai meu Jesus: crônicas de amor e sexo. Rio de Janeiro: Bertrand Brasil, 2012.

Espero alguém. Rio de Janeiro: Bertrand Brasil, 2013.

Curinga. Porto Alegre: Arquipélago, 2014.

Para onde vai o amor? Rio de Janeiro: Bertrand Brasil, 2015.

CONNELL, Raewyn. Masculinities. $2^{\mathrm{a}}$ ed. Berkeley: University of California Press, 2005.

COURTINE, Jean-Jacques. Robustez na cultura: mito viril e potência muscular. In: CORBIN, Alain; COURTINE, Jean-Jacques; VIGARELLO, Georges. História da virilidade. v. 3: a virilidade em crise? Vozes, 2013.

KIMMEL, Michael S. A produção simultânea de masculinidades hegemônicas e subalternas. Horizontes antropológicos, n. 9, 1998.

MONTEIRO, Marko. Masculinidades em revista: 1960-1990. In: DEL PRIORE, Mary; AMANTINO, Marcia. (Orgs.). História dos homens no Brasil. São Paulo: UNESP, 2013.

NOLASCO, Sócrates. A desconstrução do masculino: uma contribuição crítica à análise de gênero. In: (Org.). A desconstrução do masculino. Rio de Janeiro: Rocco, 1995.

O mito da masculinidade. Rio de Janeiro: Rocco, 1993.

PAIVA, Marcelo Rubens. O homem que conhecia as mulheres. Rio de Janeiro: Objetiva, 2006.

PEREIRA, Carlos Alberto Messeder. Que homem é esse? O masculino em questão. In: NOLASCO, Sócrates (org.). A desconstrução do masculino. Rio de Janeiro: Rocco, 1995.

SÁ, Xico. Modos de macho \& modinhas de fêmea: a educação sentimental do homem. 3. ed. Rio de Janeiro: Record, 2008.

Chabadabadá: aventuras e desventuras do macho perdido e da fêmea que se acha. Rio de Janeiro: Record, 2010. 
Os machões dançaram: crônicas de amor \& sexo em tempos de homens vacilões. Rio de Janeiro: Record, 2015.

VERISSIMO, Luis Fernando. Comédias da vida privada. 14. ed. Porto Alegre: L\&PM, 1995. O popular. $3^{\mathrm{a}}$ ed. Porto Alegre: L\&PM, 1984.

. A grande mulher nua. $2^{\mathrm{a}}$ ed. Rio de Janeiro: José Olympio, 1976. . Amor brasileiro. Porto Alegre: L\&PM, 1986.

. Ed Mort e outras histórias (1979). 5ª ed. Porto Alegre: L\&PM, 1983.

. Sexo na cabeça. Porto Alegre: L\&PM, 1980.

. O analista de Bagé. Porto Alegre: L\&PM, 1981.

. Outras do analista de Bagé. Porto Alegre: L\&PM, 1982.

. A velhinha de Taubaté. $4^{\mathrm{a}}$ ed. Porto Alegre: L\&PM, 1984.

. A mulher do Silva. Porto Alegre: L\&PM, 1984.

. A mãe do Freud. 10. ed. Porto Alegre: L\&PM, 1985.

. O marido do Dr. Pompeu. Porto Alegre: L\&PM, 1987.

. Orgias (1989). Porto Alegre: L\&PM, 1998.

. Peças íntimas. Porto Alegre: L\&PM, 1990.

. O suicida e o computador. Porto Alegre: L\&PM, 1992.

VILELA, Luiz. Tarde da noite. 5. ed. São Paulo: Ática, 1999. 